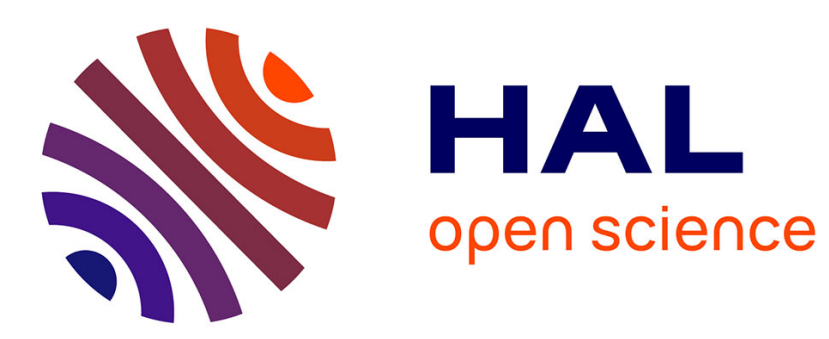

\title{
A top-down analysis for Reconstruction
}

Nicolas Guilliot

\section{To cite this version:}

Nicolas Guilliot. A top-down analysis for Reconstruction. Lingua, 2006, 116 (11), http://www.sciencedirect.com/science/journal/00243841. hal-00437089

\section{HAL Id: hal-00437089 \\ https://hal.science/hal-00437089}

Submitted on 28 Feb 2019

HAL is a multi-disciplinary open access archive for the deposit and dissemination of scientific research documents, whether they are published or not. The documents may come from teaching and research institutions in France or abroad, or from public or private research centers.
L'archive ouverte pluridisciplinaire HAL, est destinée au dépôt et à la diffusion de documents scientifiques de niveau recherche, publiés ou non, émanant des établissements d'enseignement et de recherche français ou étrangers, des laboratoires publics ou privés. 


\title{
A TOP-DOWN ANALYSIS FOR RECONSTRUCTION ${ }^{1}$ Nicolas GUILLIOT \\ University of Nantes, LLING (Laboratoire de Linguistique de Nantes) \\ nico.guilliot@gmail.com
}

\begin{abstract}
In this paper, I argue for a top-down derivational approach to reconstruction facts. I defend two related proposals to account for some puzzling and unresolved data on reconstruction regarding resumption, relativization and cyclicity. First, I argue for a syntactic top-down derivation in the sense of Phillips (1996) and Richards (1999). Second, I argue that the assignment of semantic values to any referential expression throughout the interpretation procedure also operates derivationally and in parallel with the syntactic derivation. This analysis will be supported mainly by data from Breton, but also from Welsh (Rouveret, 2002), Italian (Bianchi, 1995), Lebanese Arabic (Aoun, Choueiri \& Hornstein, 2001), and English (Fox, 2000).
\end{abstract}

Keywords: Reconstruction, Resumption, Relativization, Top-down derivation. 


\section{Introduction: what is reconstruction?}

The study of reconstruction in the literature has led to many interesting questions and paradoxes, particularly with respect to resumption, apposition and cyclicity.

The overall phenomenon of reconstruction concerns the interaction between movement and interpretation. This paper deals exclusively with a subset of reconstruction phenomenon: the interaction between A'-movement (relativization, topicalization, dislocation, wh-movement) and binding conditions (condition A, B, C and Variable Binding). We will assume a standard view of binding conditions where Condition A requires local A-binding ${ }^{2}$ of an anaphor by its antecedent (c-command), Condition B prevents pronouns from being locally A-bound, Condition C prevents R-expressions from being A-bound anywhere, and a condition on Variable Binding which ensures that a pronoun or an anaphor can be interpreted as a bound variable iff it is A-bound by a quantified expression. ${ }^{3}$

The problem of reconstruction lies in the fact that binding conditions are defined through c-command, and that any displacement modifies the c-command relations in a sentence. (1) is a well-known example showing reconstruction effects:

(1) * [Which photograph of $\left.\mathrm{John}_{\mathrm{i}}\right]_{\mathrm{j}}$ did he $\mathrm{i}_{\mathrm{i}}$ give j to Mary?

The R-expression John is subject to condition C: it must be free everywhere in the sentence. Reconstruction was originally proposed to account for the ungrammaticality of (1) (the fact that John and he cannot co-refer): the moved constituent is literally 'reconstructed' in the extraction site, thus yielding the required condition $\mathrm{C}$ violation which filters out the derivation. 


\subsection{The copy theory of movement}

Within the minimalist program, reconstruction is accounted for by the copy theory of movement (e.g. Lebeaux, 1990; Chomsky, 1995; Sauerland, 1998; among others), which predicts the following interaction between movement and binding conditions:

(2) $*\left[\left[\text { which photograph }{ }_{j} \text { of } \mathrm{John}_{\mathrm{i}}\right]_{\mathrm{j}}\left[\mathrm{did}_{\mathrm{i}} \mathrm{e}_{\mathrm{i}} \text { give [which photograph of John }\right]_{\mathrm{j}}\right]_{\mathrm{j}}$ to Mary ]]

The ungrammaticality of (1) follows from the copy theory of movement. The copy of John in the original site triggers a condition C violation: it is bound by the pronoun he.

Under this analysis, the movement of any XP leads to a reconstruction effect of that $\mathrm{XP}$ : in the appropriate configuration, the copy either triggers a condition $\mathrm{C}$ violation, or allows condition A and Variable Binding to be satisfied.

\subsection{Arguments for the copy theory of movement}

This section restates two major arguments for the copy theory of movement, based on two well-known asymmetries in reconstruction facts:

-the asymmetry between restrictive and appositive relatives -the asymmetry between movement and resumption. ${ }^{4}$

\subsubsection{Argument \#1: restrictive relatives vs appositive relatives}

The asymmetry between restrictive and appositive relatives with respect to reconstruction provides a strong argument for the copy theory of movement, as Bianchi (1995) argues.

This argument is based on the head-raising analysis for restrictive relatives (e.g. Vergnaud, 1974; Kayne, 1994). Under this analysis, restrictive relatives are derived via 
movement of the antecedent itself, whereas an appositive relative is derived via movement of a lexical or null operator co-indexed with the antecedent. ${ }^{5}$ Assuming this analysis of restrictives vs appositives, the copy theory of movement makes the following prediction developed in Figure 1: restrictive relatives should exhibit reconstruction effects; appositive relatives should not.

\section{[FIGURE 1 NEAR HERE]}

As is the case in Italian (see Bianchi, 1995), this prediction seems to be borne out in Breton if we consider the following contrast with respect to reconstruction with condition $\mathrm{C}$ :

\section{$\underline{- \text { Restrictive relative and condition } C \text { : }}$}

(3) *Pep [poltred Yann $\left.{ }_{i}\right]_{j}$ en deus pro $_{i}$ gwelet __ every picture Yann $\quad p r t^{6}$-has seen $\quad$ prt-is been torn

Every picture of Yann ${ }_{i}$ that he $\mathrm{i}_{\mathrm{i}}$ saw has been torn. ${ }^{7}$

\section{-Appositive relative and condition $C$ :}

(4) Poltred-mañ $\tilde{\mathbf{j}}_{\mathbf{j}} \mathbf{Y a n n}_{\mathbf{i}}$, [cP $\boldsymbol{\emptyset}_{\mathbf{j}}$ en deus pro ${ }_{\mathrm{i}}$ roet __j da Vari ], a zo bet drailhet.

$$
\text { picture-this Yann prt-has given to Mary prt-is been torn }
$$

'This picture of $\mathrm{Yann}_{\mathrm{i}}$, which he $\mathrm{i}_{\mathrm{i}}$ gave to Mary, has been torn.'

In (3), the restrictive reading of the relative triggers a condition $\mathrm{C}$ violation (the embedded subject cannot co-refer with Yann). In (4), condition C is satisfied with the appositive reading of the relative (coreference between Yann and the embedded subject is possible). 
The copy theory of movement straightforwardly accounts for the above contrast. The extraction site in a restrictive relative is occupied by a copy of the antecedent (triggering reconstruction effects) whereas the extraction site in an appositive relative is filled with a copy of the null operator.

\subsubsection{Argument \#2: movement vs resumption}

Another strong argument for the copy theory of movement is provided, in such languages as Breton, by the asymmetry between the direct strategy for relativization and the resumptive strategy. Under the direct strategy, the relativized position is empty. Under the resumptive strategy, the relativized position is occupied by a resumptive pronoun. In Breton, these two strategies are in complementary distribution: direct relativization whenever the local subject or the local object is relativized, and resumption in all other contexts. Moreover, these two strategies in Breton clearly differ from each other with respect to standard diagnostics for movement. Several phenomena such as island effects or weak crossover effects indicate that direct relativization is derived by movement whereas no movement is involved with resumption. Consider the following contrasts:

\section{-Island Effects:}

(5) *An den ${ }_{i}\left[\right.$ a anevez [NP an dud $d_{j}\left[\right.$ o deus d $_{j}$ j gwelet __i ] ] ] the man prt you-know the people prt-have seen 'the $\operatorname{man}_{\mathrm{i}}$ that you know the people $\mathrm{who}_{\mathrm{j}} \mathrm{saw}^{\prime}$

(6) $\operatorname{Anden}_{\mathrm{i}}\left[\mathrm{a}\right.$ anevez [NP an $\operatorname{dud}_{\mathrm{j}}$ [ o deus _ $\mathrm{j}_{\text {gwelet anezhañ }}$ ]]] the man prt you-know the people prt-have seen him 'the $\operatorname{man}_{\mathrm{i}}$ that you know the people $\mathrm{who}_{\mathrm{j}}$ saw himi' 


\section{-Weak Crossover Effects:}

(7) * Pep deni $\left[\begin{array}{llll}\text { a gare } & \left.e_{i} \text { vamm } \quad \text { i }\right]\end{array}\right.$

every man prt loved his mother

'Every $\operatorname{man}_{\mathrm{i}}$ that his $\mathrm{s}_{\mathrm{i}}$ mother loved'

(8) Pep $\operatorname{den}_{i}$ [ a lares [CP e kare $e_{i}$ vamm anezhañ $\left.\left.\tilde{n}_{i}\right]\right]$

every man prt you-say prt loved his mother him

'Every $\operatorname{man}_{i}$ that you say that his ${ }_{i}$ mother loved '

In (5) and (6), a complex-NP island is present in the derivation: relativization of the (non-local) object position of the embedded relative cannot be derived via movement. The use of the direct strategy to create the chain $\left(a n d^{2} n_{i}, \ldots i\right)$ in (5) results in ungrammaticality. However, the insertion of a resumptive pronoun in (6) rescues the sentence. The island constraint is satisfied.

The contrast between (7) and (8) also suggests that no movement occurs with resumption. ${ }^{8}$ The use of the direct strategy in (7) yields a weak crossover effect, i.e. variable binding of his $s_{i}$ by the antecedent every $\operatorname{man}_{i}$ is impossible because movement of the antecedent crosses the anaphoric element his. Thus, (7) cannot be assigned the interpretation 'every man $x$, such that the $x^{\prime}$ s mother loved $x^{\prime} .{ }^{9}$ In contrast, the resumptive strategy for relativization in Breton does not trigger any weak crossover effect, as shown in (8).

On the basis of data in Breton, we argue, following (Rouveret, 2002), that resumption is a kind of Last Resort strategy, in the sense that it is enforced only when movement (the preferred option) is banned. ${ }^{10}$ Recall that the resumptive strategy in Breton is forced for all 
extraction cases, except the extraction of local subject or object. The view of resumption as a last resort strategy leads to a potential problem: why do we need resumption in Breton for the extraction of an embedded object, which is expected to be easily accessible for movement? ${ }^{11}$

(9) An deni a lares he deus Mari eni gwelet the man prt you-say prt has Mary $\mathrm{Cl}$ seen 'the man that you say that Mary has seen'

(10) The $\operatorname{man}_{i}$ that you say that Mary has seen _-

A possible answer to this problem could be given if we adopt (Jouitteau, forthcoming)'s idea that verbs in Breton have nominal properties. In particular, objects in Breton are not assigned accusative case, but rather genitive. The object of gwelet ('seen') in (9), en ('him'), corresponds to a genitive clitic. The claim that VPs in Breton have nominal properties might shed some light on the reason why the extraction of a non-local object forces the use of resumption in Breton. However, we leave this question open here. As far as the present discussion is concerned, we will merely assume that there are some constraints (partly based on locality considerations) that account for the complementary distribution between movement and resumption. ${ }^{12}$

Now, if we assume that the direct strategy involves movement whereas resumption does not, the copy theory of movement makes another interesting prediction with respect to reconstruction schematized in Figure 2: direct strategy should exhibit reconstruction effects, but resumption should not since no movement occurs with this strategy

[FIGURE 2 NEAR HERE] 
Again, the prediction seems to be confirmed in Breton. Considering reconstruction with condition C, a clear contrast in grammaticality appears between (11) and (12):

\section{$\underline{\text {-Direct strategy and condition } C:}$}

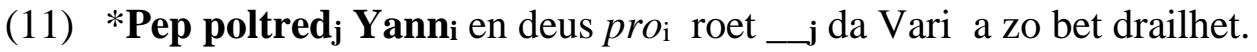
every picture Yann prt-has he given to Mary prt is been torn 'Every picture of Yann ${ }_{i}$ that he $i_{i}$ has given to Mary has been torn'

\section{$\underline{- \text { Resumptive strategy and condition } C:}$}

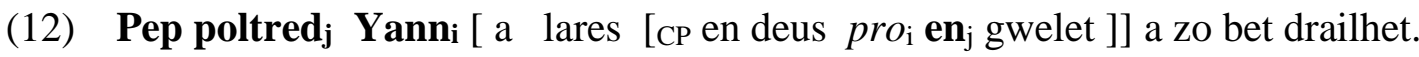
every picture Yann prt you-say prt-has he it seen prt is been torn 'Every picture of Yann $_{\mathrm{i}}$ that you say that he $\mathrm{i}_{\mathrm{i}}$ has seen has been torn.'

In the same way that apposition seems to rescue a condition C violation in (4), the use of the resumptive strategy in (12) also saves the derivation: the appearance of the resumptive clitic en in the original site allows condition $\mathrm{C}$ be satisfied (coreference between Yann and the embedded null subject becomes available).

The distinction between direct relativization and resumption, as well as the contrast between restrictive and appositive relatives, provides strong support for an analysis of reconstruction facts based on the copy theory of movement.

\section{Problems and Paradoxes}

The copy theory of movement seems to be adequate to account for reconstruction facts because it predicts the two asymmetries illustrated with condition $\mathrm{C}$ in the previous section: 
restrictive vs appositive relatives, and movement vs resumptive strategy. However, this assumption makes a very strong prediction, namely that only movement should lead to reconstruction effects.

The following section will show that the copy theory of movement on its own cannot account for all the reconstruction facts. We will now present a number of paradoxes involving the interaction of reconstruction with resumption, apposition and cyclicity.

\subsection{Reconstruction and resumption}

The first paradox that we need to account for concerns the interaction of reconstruction with resumption. As an illustration, consider reconstruction and resumption in relative clauses in Breton ((13)a is partly repeated from (12)):

(13) a. Pep poltred $\mathbf{Y}_{\mathbf{j}}$ Yann $_{\mathbf{i}}$ [ a lares [CP en deus pro $\mathbf{e n}_{\mathrm{j}}$ gwelet ]] 'Every picture ${ }_{j}$ of Yann $n_{i}$ that you say that he $e_{i}$ has seen'

b. Poltred $e_{\mathrm{i}}$ verc'h [ a lares [cP e wel pep $\left.\left.\operatorname{tad}_{\mathrm{k}} \mathbf{a n e z h a n ̃ ~}_{i}\right]\right]$ picture his daughter prt you-say prt sees every father it 'the picture $\mathrm{i}_{\mathrm{i}}$ of his $\mathrm{k}_{\mathrm{k}}$ daughter that you say that every father $\mathrm{k}_{\mathrm{k}}$ is looking at $\left(\mathrm{it}_{\mathrm{i}}\right)^{\prime}$

c. poltred $_{j}$ diouti $_{i}$ hec'h-unan $_{i}\left[\text { a zo Mari }{ }_{i} \text { lorc'h enni gantañ } \tilde{n}_{j}\right]^{13}$ picture about herself prt is Mary proud with-it

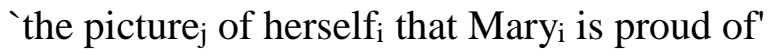

Recall that a typical property of the resumptive strategy in Breton is the fact that it exhibits clear diagnostics of a non-movement strategy, i.e. lack of sensitivity to islands and 
lack of weak crossover effects (see 1.2.2). The copy theory of movement would then predict the absence of any reconstruction effect with resumption. Condition $\mathrm{C}$ confirms this prediction as coreference between Yann and the subject of the relative in (13)a is possible. Resumption rescues the condition $\mathrm{C}$ violation: no copy of the antecedent appears in the relativized site.

However, reconstruction with variable binding and condition A cannot be handled by the copy theory of movement. Indeed, both (13)b and c show reconstruction effects. In (13)b, the pronoun 'his' $(e)$ embedded inside the antecedent of the relative can be bound by the quantified constituent 'every father' (pep tad), itself embedded in the relative clause. In (13)c, the anaphor diouti hec'h-unan can also be bound by the embedded antecedent Mari.

The copy theory of movement cannot explain why (13)b and c are grammatical: if resumption does not involve movement, how do we account for these reconstruction effects?

Aoun, Choueiri and Hornstein (2001) provide similar examples illustrating the interaction of reconstruction with resumption in dislocation structures in Lebanese Arabic. Compare (13)b with (14):

\section{-Resumptive strategy and variable binding (in Lebanese Arabic):}

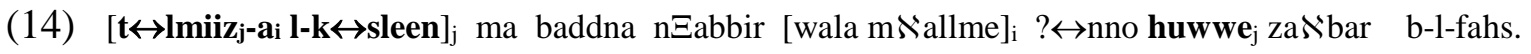
student-her the-bad neg want.1pl say no teacher.fem that he cheated on-the-exam 'her ${ }_{i}$ bad student ${ }_{j}$, we don't want to tell any teacher ${ }_{i}$ that he ${ }_{j}$ cheated on the exam.'

In (14), the resumptive pronoun 'he' (huwwe) is bound by the dislocated constituent. If we assume that resumption is derived without movement, the copy theory of movement would then predict the absence of any reconstruction effect. However, reconstruction effects appear, since the pronoun 'her' $(-a)$ inside the dislocated constituent can be bound by the 
quantified element 'no teacher' (wala $m$ s'allme). That is, (14) allows a bound variable reading where there can be a different student for each teacher. ${ }^{14}$

\subsection{Reconstruction in appositive relatives}

The same kind of contrast appears when we study the interaction of reconstruction with apposition. Consider the contrast in Breton between (15)a (repeated from (4)), which does not trigger reconstruction (otherwise condition $\mathrm{C}$ would be violated), and (15)b, which triggers reconstruction (since condition A is satisfied):

(15) a. [Poltred-mañ Yann $]_{\mathrm{j}}, \varnothing_{\mathrm{j}}$ en deus proi roet $[\varnothing]_{\mathrm{j}}$ da Vari, a zo bet drailhet.

'This picture of $\mathrm{Yann}_{\mathrm{i}}$, which he $\mathrm{i}_{\mathrm{i}}$ gave to Mary, has been torn.'

b. [Poltred-mañ diouti hec'h-unan $]_{\mathrm{i}}$, he deus roet Mari $\mathrm{i}_{\mathrm{i}}$ da Yann, a zo bet drailhet. picture-this about herself prt-has given Mary to Yann prt is been torn 'This picture of herself $f_{i}$, which Maryi gave to Yann, has been torn.'

On a par with resumption, appositive relativization should not be compatible with reconstruction as the copy theory of movement will provide only a copy of the null operator in the relativized site. Condition C follows the expected pattern. In (15)a, repeated from (4), coreference between Yann and the subject of the appositive relative is possible. The absence of any reconstruction effect is predicted by the copy theory of movement. The appositive relative is derived through movement of a null operator co-indexed with the antecedent 'picture'. Hence, there is no copy of the antecedent triggering a condition $\mathrm{C}$ violation.

However, condition A unexpectedly exhibits reconstruction effects with the appositive relative. In (15)b, the anaphor diouti hec'h-unan ('herself') can take the subject of the 
appositive relative (Mari) as its antecedent, as if the antecedent were reconstructed in the extraction site of the appositive relative.

Now what about variable binding? As was the case for resumption, we might expect appositive relatives to exhibit unexpected cases of reconstruction with variable binding. However, this is not the case, as the ungrammaticality of (16) shows:

(16) $*\left[\text { Poltred-mañ } \mathbf{e}_{\mathbf{i}} \text { verc'h }\right]_{\mathrm{j}}, \varnothing_{\mathrm{j}}$ a gare pep tad $\mathrm{d}_{\mathrm{i}}[\varnothing]_{\mathrm{j}}$, a zo bet drailhet. picture-this his daughter prt loved every father prt is been torn *`This picture of hisi daughter, which every father ${ }_{i}$ liked, has been torn.'

(16) might appear to contradict the parallel we have established between apposition and resumption with respect to reconstruction. However, the ungrammaticality of (16) is not due to a lack of reconstruction, but to the semantic incompatibility between variable binding of 'his' $(e)$, which yields a distributed reading of the antecedent, and the fact that an appositive relative requires a specific interpretation of the antecedent of that relative. In other words, there might be reconstruction in this case, but the derivation crashes because of a mismatch in interpretation. This conclusion is confirmed by the fact that the sentence remains ungrammatical even if the reconstruction problem is eliminated, as (17) shows:

(17) * Sellout a ra pep tad i $_{i} \quad$ ouzh poltred-mañ $\mathrm{e}_{\mathrm{i}}$ verc'h, am eus choazet. watch prt does every father against picture-this his daughter prt-I have chosen

*`Every father i is looking for this picture of her ${ }_{i}$ daughter, which I have chosen.'

The ungrammaticality of (16) must be accounted for independently of the issue of reconstruction. However, the contrast in reconstruction facts between condition $\mathrm{C}$, which does 
not trigger reconstruction, and condition $\mathrm{A}$, which does trigger reconstruction, still remains to be explained, and the copy theory of movement fails to do so.

This surprising contrast in reconstruction between condition A and condition $\mathrm{C}$ was first noticed by Bianchi (1995) in Italian. The examples are given in (18):

(18) a. La recensione del libro di Gianni $i_{i}$, che pro $_{\mathrm{i}}$ si è rifiutato di leggere, era negativa. the criticism of-the book of Gianni which ref has refused to read was negative 'The criticism of the book by Gianni $i_{i}$, which he ${ }_{i}$ refused to read, was negative.'

b. ? Questi aspetti della propriai personalità, che Gianni ${ }_{i}$ non riesce ad accettare, sono these aspects of-his own personality which Gianni not able to accept were emersi nel corso dell'analisi.

emerged in-the course of-the analysis

'These aspects of his ${ }_{i}$ own personality, which Gianni $i_{i}$ was unable to accept, emerged during the psychoanalysis.'

As was the case in Breton, reconstruction facts with condition $\mathrm{C}$ in Italian are straightforwardly accounted for by the copy theory of movement. The grammaticality of (18)a with coreference between Gianni and the subject of the appositive relative is due to the fact that apposition is derived via movement of an operator co-indexed with the antecedent 'aspects' (aspetti). Hence, no reconstruction effects will arise, as expected.

However, the contrast between condition $\mathrm{C}$ and condition $\mathrm{A}$ is puzzling. Indeed, in (18)b, the anaphor propria is subject to condition A: it has to be c-commanded by its antecedent. The appositive relative in (18)a exhibits reconstruction effects, since the anaphor 
can take Gianni, the subject of the appositive, as its antecedent. This reconstruction effect with apposition is clearly unexpected under the copy theory of movement.

\subsection{Reconstruction and cyclicity}

Cyclicity roughly entails that movement must operate locally and in a bottom-up fashion. Indeed, most traditional analyses assume a cyclic derivation based on the existence of intermediate sites for movement. One major argument for a cyclic view of movement is based on reconstruction facts. ${ }^{15}$ Consider the following contrast first given in (Lebeaux, 1990), and then reanalysed in (Heycock, 1995) and (Fox, 2000):

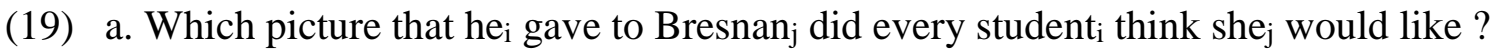

b. ${ }^{*}$ Which picture that he ${ }_{i}$ gave to Bresnan ${ }_{j}$ did she $_{j}$ think every student $t_{i}$ would like ?

In (19)a, the reading where he is bound by every student and she co-refers with Bresnan is grammatical. In contrast, (19)b is ungrammatical under this reading.

The extensively discussed contrast between (19)a and $b$ has been taken to argue for intermediate landing sites for movement. Intuitively, the only way to satisfy variable binding and condition C simultaneously in (19)a is to assume the existence of an intermediate landing site for the displaced constituent, as illustrated in (20) from (Fox, 2000):

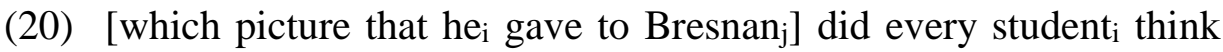
she $_{\mathrm{j}}$ would like $* ?^{16}$

In contrast, no such site is available in (19)b: the pronoun she c-commands the quantified expression every student; hence, there is no way to satisfy variable binding without inducing a condition C violation, as shown in (21) from (Fox, 2000): 
(21) [which picture that he $\mathrm{i}_{\mathrm{i}}$ gave to Bresnan $\mathrm{j}_{\mathrm{j}}$ ] did she $\mathrm{j}_{\mathrm{j}}$ think $\quad$ * every student $\mathrm{i}_{\mathrm{i}}$ would like $* ?^{17}$

Fox (2000) further argues for multiple target sites for reconstruction even within the same IP domain, on the basis of examples such as (22):

(22) a. [Which of the books that he $\mathrm{i}_{\mathrm{i}}$ asked Mrs Brown $\mathrm{B}_{\mathrm{j}}$ for] did every student $\mathrm{i}_{\mathrm{i}}$ get from $\operatorname{her}_{\mathrm{j}} \stackrel{*}{ }$ ?

b. *[Which of the books that he $\mathrm{i}_{\mathrm{i}}$ asked Mrs Brown $\mathrm{j}_{\mathrm{j}}$ for] did she $\mathrm{j}_{\mathrm{j}} *$ give every student $_{\mathrm{i}} \stackrel{*}{ }$ ?

To account for the contrast in (22), Fox suggests that several sites for reconstruction in the same IP domain need to be posited: one in the argument position and one at the edge of the VP. Assuming that reconstruction follows from the copy theory of movement in Fox's analysis, the contrast in (22) also entails that movement must be derived in order to provide in (22)a a copy of the moved constituent in the scope of every student but outside the scope of her. Within a minimalist framework, this means that a feature needs to be posited in every site where reconstruction is possible, in order to ensure that a copy of the displaced constituent appears in the required reconstruction sites. In other words, as Richards (1999: 19) points out, the existence of intermediate landing sites follows only from the existence of stipulated features that need to be checked.

In this section, we have seen several cases of reconstruction which cannot be reduced to the copy theory of movement, in particular data involving resumption or apposition. 
We will show in the next section that these puzzling paradoxes regarding reconstruction can be given a straightforward account once we adopt a top-down syntactic and semantic derivation. Moreover, we will further argue that the existence of intermediate sites for reconstruction (see the intricate patterns shown in (19) and (22)) simply follows from this top-down approach without the need to appeal to any feature triggering cyclic movement.

\section{A top-down approach to reconstruction}

I defend two related proposals: a top-down syntactic derivation in the sense of Phillips (1996) and Richards (1999), and a semantic derivation which proceeds in parallel with the syntactic derivation. The central claim underlying this analysis is that the interpretation procedure (i.e. the semantic calculus) is not carried out after, but rather in parallel with the syntactic derivation which itself unfolds top-down. The approach advocated here makes a strong claim: not only can syntax feed semantic operations, but the semantic calculus can itself trigger syntactic operations as well. The results achieved are thus in the spirit of Reinhart (1995) and Fox (2000), but from a different angle. ${ }^{18}$

\subsection{The premises}

The proposal is based on the interaction between the syntactic and the semantic derivations in a top-down fashion. The question remains as to how these two derivations are implemented.

\subsubsection{Semantic calculus and Binding Theory}

Traditionally, binding conditions are considered as filters on representations, that is indices are freely assigned, and binding conditions then apply to filter out illicit patterns of distribution. 
We argue here that it is the assignment procedure of semantic indices to referential expressions which is itself constrained by the Binding Theory, and not the output of this assignment procedure. In other words, Binding Theory governs the assignment of semantic indices during the course of the derivation.

As far as the semantic calculus is concerned, we propose that any referential expression receives its semantic value as soon as it enters the syntactic derivation. We further assume the following distinction between two kinds of referential expressions: R-expressions on the one hand; and pronouns and anaphors on the other hand (a distinction partially assumed in (Schlenker, 2003)):

-An R-expression is assigned a semantic value as soon as it is inserted into the derivation, as it can refer independently. The assignment of this index is constrained by condition $\mathrm{C}$.

-Pronouns and anaphors are variables: they get their semantic index from an antecedent in the linguistic context. This corresponds to the definition of variable given in (Heim, 1993). For her, all indices qualify as variables. Moreover, variables (that is, indices) are subject to well-formedness conditions. In particular, they need to be A-bound. ${ }^{19}$ We will refer to these elements as pronoun or $^{\text {anaphor }}$ as their referential index (x) has not yet been assigned. The assignment of a referential value to a $\operatorname{pronoun}_{\mathrm{x}}$ or anaphor $_{\mathrm{x}}$ is constrained by condition A for an anaphor ${ }_{\mathrm{x}}$ and condition B for a pronoun $\mathrm{x}$, and by variable binding ${ }^{20}$ when the antecedent of a pronoun or anaphor $x$ is quantified. ${ }^{21}$

\subsubsection{Syntactic derivation and movement}

We argue in favour of a syntactic top-down derivation, as proposed in (Phillips, 1996), for whom phrase markers are built up incrementally and the derivation proceeds linearly from 
left to right. Moreover, following (Richards, 1999), we assume two ways of creating dependencies in a top-down approach, which we dub ' $\theta$-motion' and 'Subsiding'.

$\theta$-motion is based on what Richards calls 'traditional movement'. It is a top-down mechanism by which a copy $\theta$ of a displaced phrase $\alpha$ is created only in the $\theta$-position. Richards, in his system, does not assume that 'traditional movement' is cyclic. He tries to eliminate unmotivated features that are required in a minimalist view to enforce the cyclicity of movement (see Richards, 1999: 19).

However, some data, and in particular reconstruction facts, argue in favour of the cyclicity of movement. This is where Subsiding operates. Subsiding is also a top-down mechanism based on Richards' idea of 'Sinking'. The difference between sinking and $\theta$ motion lies in the fact that the copy of a displaced phrase $\theta$ is created as soon as this phrase $\alpha$ is inserted in the tree, and then this copy sinks down the tree, as material is merged inbetween, as (23) shows:

(23) Sinking/Subsiding:
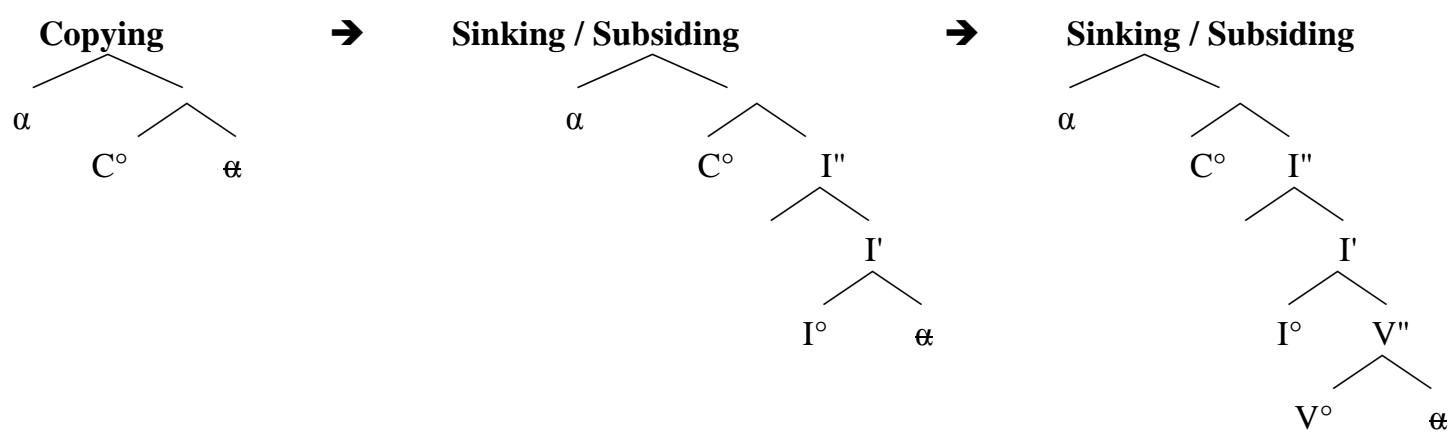

To implement this rather new kind of movement, Richards (1999: 15) gives the following restriction on Merge:

(24) Merge $\alpha$ to a position which c-commands as few nodes as possible. 
For Richards, material can be merged above the copy created by sinking (see (23)) as long as this copy has not reached a position where it can land. This gives rise to a kind of successive cyclic movement of the copy, referred to as sinking, and which we will dub 'Subsiding'.

The next question, where my proposal departs from that of Richards, concerns the activation of these two mechanisms to create dependencies. When and how are subsiding and $\theta$-motion activated? Richards leaves this question open.

I assume that $\theta$-motion is triggered whenever a $\theta$-feature needs to be checked by a predicate. Thus, $\theta$-motion always targets $\theta$-positions and the trigger will be any predicate whose $\theta$-grid needs to be saturated. As an illustration, consider (25) and its top-down derivation in (26):

(25) Who did you see _ _ ?

(26) Derivation of (25):
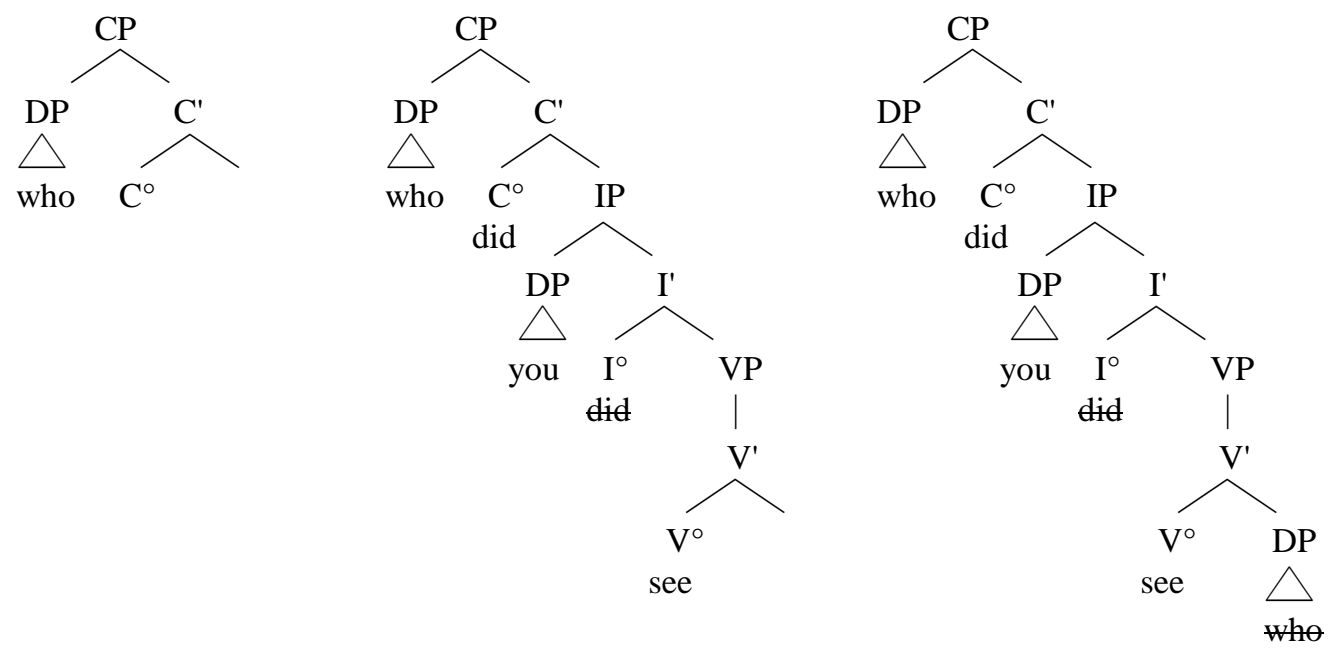

The derivation unfolds in a top-down fashion until the object position of the verb see is reached. A thematic role needs to be discharged in this position. $\theta$-motion of who will be activated in order to check that feature. ${ }^{22}$ 
Notice here that, in principle, a resumptive pronoun could just as well be merged to check this thematic role in the derivation. To distinguish between movement and resumption, we assume, following (Rouveret, 2002), that resumptive pronouns are inserted in the derivation as a last resort strategy, in order to satisfy locality constraints on movement (such as islands). This analysis is referred to as Last Resort Resumption. ${ }^{23}$

Subsiding of a displaced constituent is triggered only when a variable is present in that constituent. By variable, we mean any pronoun or anaphor which has not yet been assigned any reference in the semantic derivation, i.e. a $\operatorname{pronoun}_{\mathrm{x}}$ or anaphor $\mathrm{x}_{\mathrm{x}}$ This principle can be formulated in the following way:

(27) Subsiding is activated as a top-down last resort operation to bind a pronoun ${ }_{\mathrm{x}}$ or an anaphor $_{\mathrm{x}}$, i.e. in order to assign a referent to the pronoun or the anaphor.

(28) is an example where subsiding will be triggered because a variable (the anaphor) is present inside the displaced constituent. Let's see how the sentence is derived:

(28) [Which picture of himself $\left.]_{j}\right]_{j}$ did $J_{o h n}$ see _ ${ }_{j}$ ?

(29) Derivation of (28):

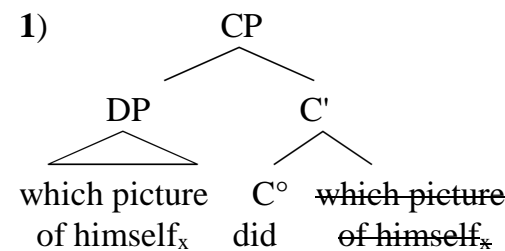

2)

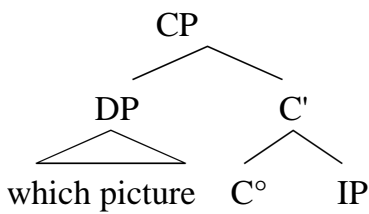

of himself $f_{i}$ did
3)

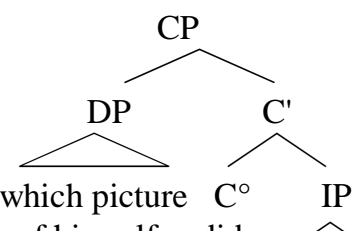

of himself $\mathrm{i}_{\mathrm{i}}$ did

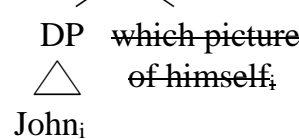

$\mathrm{John}_{\mathrm{i}}$

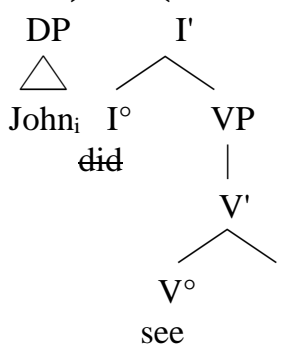


As the syntactic derivation of (28) shows, subsiding is triggered at step 1 since the displaced constituent contains the element himself $f_{x}$ which needs to get a semantic value. The copy of the displaced constituent sinks down the tree as new material is merged over it. At step 2, John is inserted in the derivation and becomes a possible antecedent for the anaphor himself as it c-commands the copy of that antecedent. At this point, we assume that subsiding can stop because there is no longer any trigger to activate it. That is, the anaphor himself $i$ is no longer searching for an antecedent. ${ }^{24}$ At step 3, new material is merged in the top-down derivation until the object position of the verb see is reached. At this step, $\theta$-motion will be triggered to fill the thematic role of the verb.

Now, we can sum up the properties of $\theta$-motion and subsiding, and see the predictions that the two mechanisms make with respect to the phenomenon of reconstruction: see Table 1 .

\section{[TABLE 1 NEAR HERE]}

To summarize, $\theta$-motion and subsiding differ in that the former is triggered by feature checking and is subject to any locality constraint that could prevent the creation of a copy in the extraction site. In contrast, subsiding is activated only when a pronoun or an anaphor has not yet been assigned a semantic index, and applies in order to create the structural configuration required for this semantic value to be assigned.

\subsection{The account}

We now show how this top-down approach to reconstruction facts can account for all the unexpected or paradoxical data presented above.

\subsubsection{Resumption and reconstruction}

Recall the paradigm of reconstruction facts with resumption, repeated from (13): 
(30) a. Condition C:

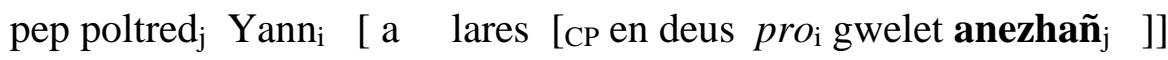
every picture Yann prt you-say prt-has he seen it 'every picture $\mathrm{j}_{\mathrm{j}}$ of $\mathrm{Yann}_{\mathrm{i}}$ that you say that he $\mathrm{i}_{\mathrm{i}}$ has seen $\left(\mathrm{it}_{\mathrm{j}}\right){ }^{\prime}$

\section{b. Variable Binding:}

$\operatorname{poltred}_{i} e_{k} \operatorname{verc} h\left[\begin{array}{llll}\text { a lares [cP e } & \text { wel } & \left.\operatorname{pep} \operatorname{tad}_{\mathrm{k}} \operatorname{anezhañ~}_{\mathbf{i}}\right]\end{array}\right]$ picture his daughter prt you-say prt sees every father it 'the picture $\mathrm{i}_{\mathrm{i}}$ of hisk daughter that you say that every father $\mathrm{k}_{\mathrm{k}}$ is looking at (it $\left.\mathrm{i}_{\mathrm{i}}\right)^{\prime}$

\section{c. Condition A:}

poltred $_{j}$ diouti $_{i}$ hec'h-unan $_{i}$ [ a zo Mari lorc'h enni gantañ $_{j}$ ]

picture about herself prt is Mary proud with-it

'the picture $\mathrm{j}_{\mathrm{j}}$ of herself $\mathrm{f}_{\mathrm{i}}$ that Maryi is proud of $\left(\mathrm{it}_{\mathrm{j}}\right)^{\prime}$

The examples in (30) illustrate the puzzling paradox which arises from the interaction of reconstruction with resumption. Recall that the resumptive strategy in Breton exhibits properties diagnostic of a non-movement strategy, namely lack of sensitivity to islands and lack of weak crossover effects (see 1.2.2). The copy theory of movement would then predict the absence of any reconstruction effect with resumption. Although it does indeed predict the absence of reconstruction effects with condition $\mathrm{C}$ in (30)a (coreference between Yann and the embedded pro is possible), it also, however, incorrectly predicts the absence of any reconstruction effect with variable binding or condition A, contrary to facts, as both (30)b and (30)c show reconstruction effects. 
Our top-down approach to reconstruction provides a straightforward account of this contrast.

In (30)a, subsiding of the antecedent is not triggered by the semantic calculus. That is, it is not required in order to provide a semantic value for a variable (pronoun or anaphor). The top-down derivation proceeds until the object position of the verb 'see' (gwelet) is reached. At this step, a thematic role needs to be checked. In principle, two options are available to check that role: either insertion of a copy of the antecedent by $\theta$-motion, or insertion of a resumptive pronoun. In (30)a, we assume that a locality constraint forces insertion of the resumptive pronoun anezhañ in the relativized site. ${ }^{25}$ The grammaticality of the example is then accounted for as condition $\mathrm{C}$ is never violated in the course of the derivation. ${ }^{26}$

As we have seen, variable binding and condition A, as opposed to condition $\mathrm{C}$, do yield reconstruction effects even with resumption. This asymmetry follows from our approach to reconstruction. In (30)b, variable binding will be satisfied: the possessive pronoun $e$ can get bound by the quantified phrase pep tad, even when the relativization site is occupied by the resumptive pronoun anezhañ. ${ }^{27}$

To understand the grammaticality of (30)b, consider the syntactic derivation sketched in (31)(irrelevant structure omitted):
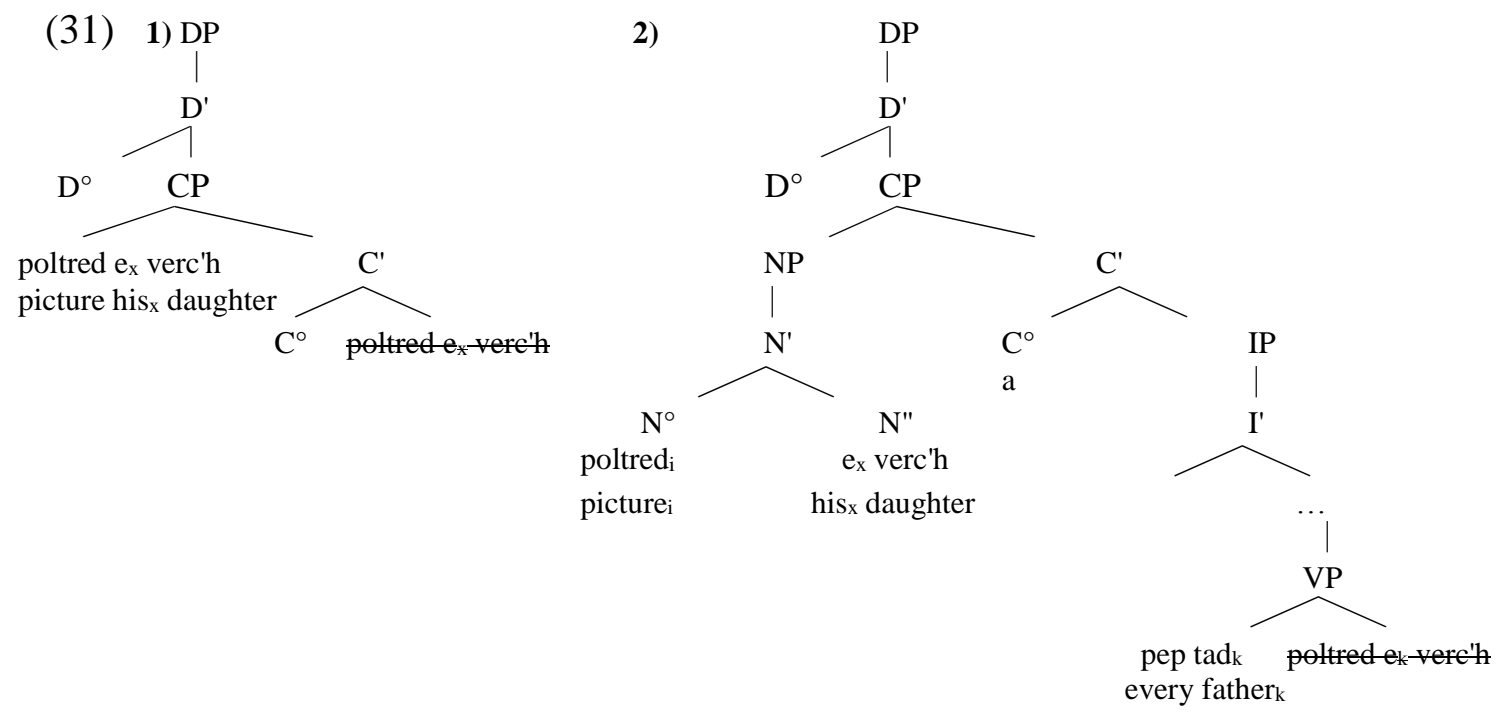
In (30)b, subsiding of the antecedent poltred e verc' $h$ will be triggered as it contains the pronoun 'his $\mathrm{x}_{\mathrm{x}}\left(e_{x}\right)$ which must acquire its semantic value. ${ }^{28}$ Once the top-down derivation reaches the quantified phrase (step 2), the resulting structural configuration allows binding by 'every father' (pep tad), thus predicting reconstruction effects. Subsiding stops once the need for it is satisfied, and the derivation carries on. At the point where the object position of the verb is reached, locality constraints force insertion of the resumptive pronoun anezhañ in the relativization site.

The same analysis carries over to (30)c, which illustrates the interaction of condition A with resumption. To account for the fact that condition $\mathrm{A}$ is satisfied, and thus for the grammaticality of the sentence, we assume that subsiding is triggered to bind the anaphor $h e c^{\prime} h-u_{n a n}$ as it needs to be assigned a semantic value. Subsiding will yield reconstruction effects: the anaphor is A-bound by Mari. At this step, subsiding is no longer triggered and stops. Finally, a resumptive element (agreement on the preposition gant) is inserted in the relativization site. ${ }^{29}$

This top-down approach to reconstruction, based on the idea of last resort subsiding in order to bind a variable (anaphor ${ }_{\mathrm{x}}$ or pronoun $_{\mathrm{x}}$ ), correctly predicts the following asymmetry with respect to the interaction of reconstruction with resumption:

-no reconstruction effect arises with condition $\mathrm{C}$ as there is no trigger for subsiding and resumption precludes any copy of the antecedent in the relativized site.

-reconstruction effects appear with variable binding and condition A as subsiding is triggered by the existence of a variable within the antecedent, which needs to acquire its semantic index. 


\subsubsection{Appositive relatives and reconstruction}

Our analysis further predicts that the same contrast in reconstruction facts should hold in appositive relatives, as (32), repeated from (15), confirms:

\section{(32) a. Condition C:}

[Poltred-mañ Yann $]_{j}, \emptyset_{j}$ en deus pro $o_{\mathrm{i}}$ roet $[\varnothing]_{\mathrm{j}}$ da Vari, a zo bet drailhet. picture-this Yann prt-has he given to Mary prt-is been torn 'This picture of $\mathrm{Yann}_{\mathrm{i}}$, which he $\mathrm{i}_{\mathrm{i}}$ gave to Mary, has been torn.'

\section{b. Condition A:}

[Poltred-mañ diouti hec'h-unan $\left.{ }_{i}\right]_{j}$, he deus roet Mari $i_{i}$ da Yann, a zo bet drailhet. picture-this about herself prt-has given Mary to Yann prt is been torn 'This picture of herself $\mathrm{f}_{\mathrm{i}}$, which Mary $\mathrm{i}_{\mathrm{i}}$ gave to Yann, has been torn.'

Appositive relatives are predicted to exhibit the same pattern of reconstruction as was observed for resumption, since the copy theory of movement will only supply a copy of the null operator in the relativized site. Condition $\mathrm{C}$ follows the expected pattern as no reconstruction effect arises in (32)a, but Condition A does not as (32)b unexpectedly exhibits reconstruction effects (condition A is satisfied). ${ }^{30}$

The lack of condition $\mathrm{C}$ effect in (32)a directly follows from our top-down syntactic and semantic derivation. There is no trigger for subsiding of the antecedent as the Rexpression Yann can acquire a semantic value independently. The derivation proceeds until the object position of 'give' (roet) is reached. The verb's thematic role will be checked via $\theta$ motion, which creates a copy of the null operator in the relativization site. This derivation 
correctly predicts the grammaticality of the sentence as condition $\mathrm{C}$ is never violated (no copy of the antecedent appears in the c-command domain of the embedded subject pro).

In contrast, in (32)b, the occurrence of the anaphor hec'h-unan ('herself $_{\mathrm{x}}{ }^{\prime}$ ) within the antecedent triggers subsiding of a copy down the tree, as sketched in (33):

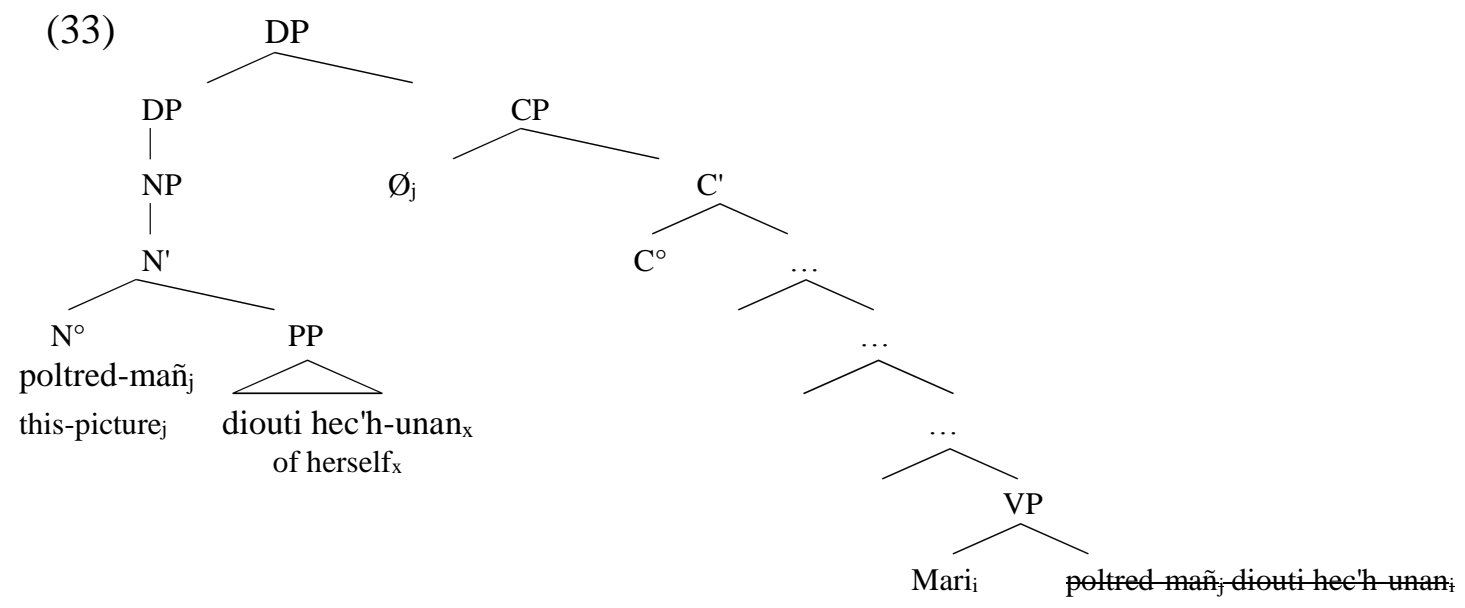

As (33) shows, the copy of the antecedent sinks down the tree until Mari is merged in the derivation. At this step, a potential antecedent for the anaphor hec'h-unan is provided. Subsiding stops. The derivation carries on and a copy of the null operator is created in the relativization site via $\theta$-motion. The grammaticality of $(32) \mathrm{b}$ is accounted for as the anaphor embedded within the antecedent of the relative can be bound by Mari.

The top-down approach to reconstruction correctly predicts the following asymmetry with respect to the interaction of reconstruction with apposition:

-no reconstruction effect appears with condition $\mathrm{C}$ since there is no trigger for subsiding and only a copy of the null operator will be provided in the relativized site.

- reconstruction effects occur with condition A since subsiding is triggered as a last resort operation to bind the anaphor in the antecedent. ${ }^{31}$ 


\subsubsection{Cyclicity and reconstruction}

The last set of puzzling data that our top-down approach to reconstruction can handle concerns the interaction of reconstruction with cyclicity.

As is argued in section 2.3, reconstruction facts point to the existence of intermediate landing sites, and thus suggest that movement is highly cyclic. This cyclicity of movement straightforwardly follows from the idea of subsiding inspired by Richards (1999). In contrast, a minimalist account based on the copy theory of movement would capture the generalization only at the cost of 'invented' and stipulated features, as argued in (Richards, 1999: 19).

Recall the following facts, repeated from (19), given in (Lebeaux, 1990):

(34) a. Which picture that he ${ }_{i}$ gave to Bresnan ${ }_{j}$ did every student $t_{i}$ think she jould $_{j}$ like?

b. *Which picture that he ${ }_{i}$ gave to Bresnan ${ }_{j}$ did she $_{j}$ think every student ${ }_{i}$ would like?

In (34)a, coreference between Bresnan and she and variable binding of he by every student are allowed simultaneously. In contrast, in (34)b, coreference and variable binding are incompatible with each other. The grammaticality of (34)a suggests the existence of an intermediate site for movement, where variable binding could be satisfied without inducing a condition C violation, as sketched in (35):

(35) [which picture that he $\mathrm{i}_{\mathrm{i}}$ gave to Bresnan $\left.{ }_{\mathrm{j}}\right]_{\text {did }}$ every student $\mathrm{t}_{\mathrm{i}}$ think she $e_{j}$ would like $*$ ?

Our top-down approach to reconstruction automatically accounts for this well-known asymmetry (see section 2.3.). 
In both (34)a and b, subsiding is triggered to bind the variable $h e_{\mathrm{x}}$ embedded in the wh-phrase. Subsiding sinks the copy down the tree. Once the highest intermediate landing site shown in (35) is reached, the variable is in the appropriate configuration to license binding. Subsiding stops once variable binding is satisfied, and condition $\mathrm{C}$ violation is thus avoided.

In (34)b, a condition $C$ violation is unavoidable. Subsiding sinks the copy down the tree. Once the lowest intermediate landing site is reached, variable binding can indeed be satisfied but condition $\mathrm{C}$ filters out the derivation.

Our analysis also accounts for the existence of multiple intermediate sites for reconstruction. Recall that Fox (2000) gives the following examples (repeated from (22)a and b) which argue for successive cyclicity of movement within the same IP domain:

(36) a. [Which of the books that he $\mathrm{i}_{\mathrm{i}}$ asked $\mathrm{Mrs} \mathrm{Brown}_{\mathrm{j}}$ for] did every student $\mathrm{i}_{\mathrm{i}}$ get from $\operatorname{her}_{\mathrm{j}} *$ ?

b. *[Which of the books that he $\mathrm{i}_{\mathrm{i}}$ asked Mrs Brown $\mathrm{j}_{\mathrm{j}}$ for] did she $\mathrm{j}_{\mathrm{j}} *$ give every student $_{\mathrm{i}} \stackrel{*}{\longrightarrow}$ ?

The grammaticality of (36)a requires the existence of a reconstruction site where the pronoun he can be bound by the quantified phrase without inducing a condition $\mathrm{C}$ violation between her and Mrs Brown. As reconstruction follows from the copy theory of movement in Fox's analysis, ${ }^{32}$ the contrast in (36) also entails that movement is higly local in order to provide in (36)a a copy of the moved constituent below every student but above her.

Thus, Fox (2000) provides strong empirical arguments in favour of multiple intermediate sites, essentially based on reconstruction facts. However, Fox does not give 
much detail on what triggers the creation of the intermediate copies within the IP domain in the first place. As pointed out by Richards (1999: 19), the minimalist way to enforce cyclic movement involves positing unmotivated features.

In contrast, the existence of multiple reconstruction sites follows automatically from our top-down approach without further stipulation, as subsiding is a successive cyclic operation by definition since the copy of a displaced phrase is created as soon as this phrase is inserted in the tree, and then this copy sinks down the tree.

In both (36)a and $b$, the occurrence of a variable in the displaced constituent triggers subsiding, as (37) shows:

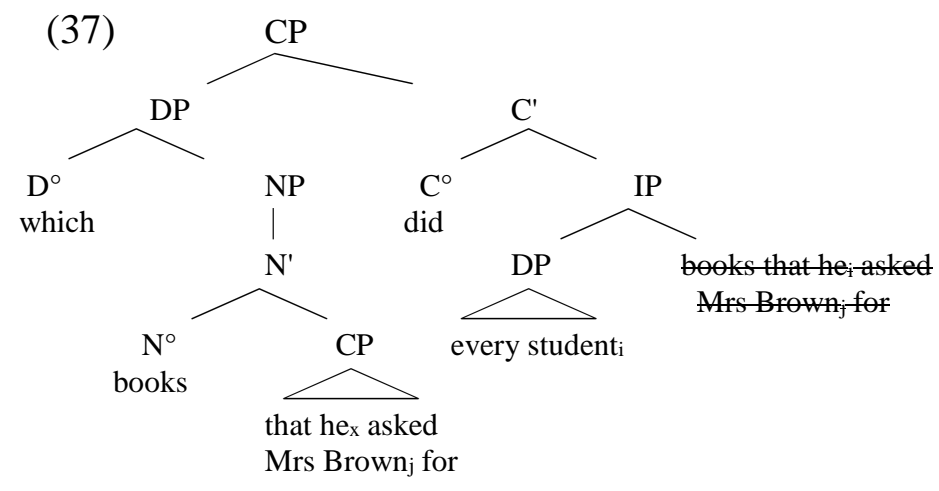

In (36)a, the copy sinks down the tree in successive cyclic fashion until every student is merged into the structure. At this step, the appropriate configuration is formed: $h e_{x}$ can be bound by the quantified phrase every student $\mathrm{t}_{\mathrm{i}}$. Condition $\mathrm{C}$ is not violated at this point of the derivation as the pronoun $h r_{\mathrm{j}}$ has not yet been merged into the structure. Subsiding can stop as the trigger for it has been satisfied. Thus, reconstruction is possible without inducing any condition C violation, hence accounting for the grammaticality of (36)a. 
In contrast, in $(36) \mathrm{b}$, the pronoun $s h e_{\mathrm{j}}$ is merged in the structure before the quantified phrase. Thus, once the copy created by subsiding reaches every student $t_{\mathrm{i}}$, the pronoun $e_{\mathrm{x}}$ can be bound but the same copy leads to a condition $\mathrm{C}$ violation involving $s h e_{\mathrm{j}}$ and $M r s$ Brown, as the derivation in (38) shows:

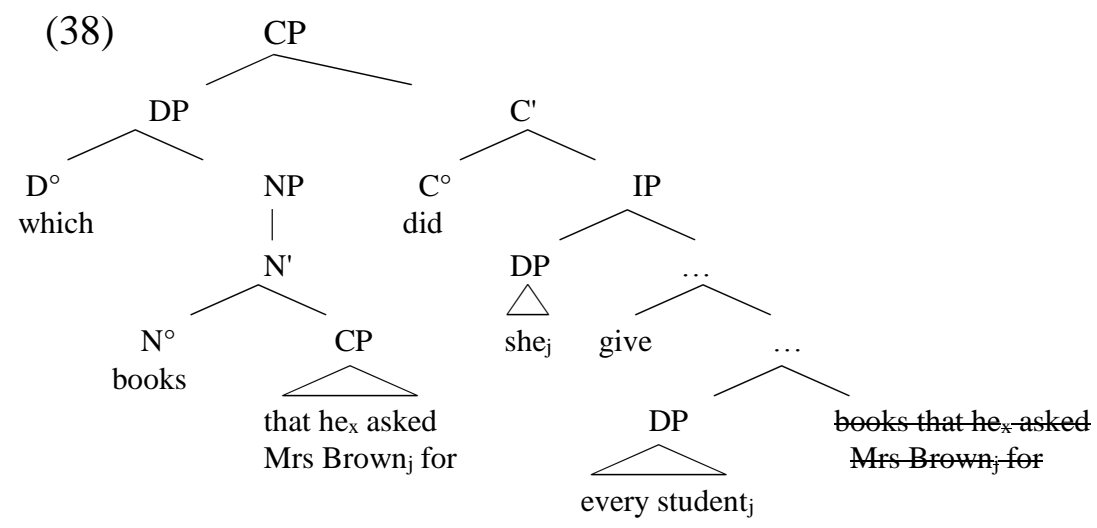

The contrast in (36), which has been used as an argument for multiple reconstruction sites, directly follows from our top-down analysis. ${ }^{33}$

In this section, we have provided several arguments which show that our top-down approach to reconstruction is on the right track. The availability of two kinds of movement, $\theta-$ motion triggered by feature checking, and subsiding triggered in order to provide a semantic value for a variable in a displaced constituent, accounts for intricate cases of reconstruction interacting with resumption, appositive relatives, and correctly predicts multiple local reconstruction sites.

\section{Further arguments: Why Top-down and not Bottom-up ?}

The top-down approach to reconstruction proposed in this paper is crucially based on two assumptions: 
-The syntactic and semantic derivations unfold in parallel and top-down.

-Subsiding is triggered as a last resort strategy in order to provide a semantic value for a variable (pronoun or anaphor) in a displaced constituent.

We will now provide support for these two assumptions coming from data in Welsh adapted from (Rouveret, 2002) and data in Italian taken from (Bianchi, 1995).

\subsection{Top-down derivation and resumption in Welsh}

Reconstruction facts with resumption in Welsh give strong support for the assumption that the derivation proceeds in a top-down fashion. ${ }^{34}$ As is the case in Breton, the occurrence of resumption in Welsh does not obviate reconstruction effects. That is, reconstruction with respect to condition $\mathrm{A}$ is compatible with resumption in (39). However, according to Rouveret, only the interpretation with the nearest potential antecedent for the anaphor ei hun is possible, i.e. Mair ('Mary').

(39) ? Fe'm hysbyswyd am [y clecs amdani ei hun?i/*j] $]_{\mathbf{k}}[\mathrm{y}$ cred Mair Prt-me was-reported about the gossip about herself that believes Mary fod Nadia ${ }_{j}$ wedi $\mathbf{e u}_{\mathbf{k}}$ clywed yn y cyfarfod ] be Nadia Perf $\mathrm{Cl}$ hear at the meeting

'I was informed of the gossip about herself $?_{?_{i} / *_{j}}$ that Mary $y_{i}$ thinks that Nadia $a_{j}$ heard at the meeting.'

Under a top-down approach to reconstruction, these facts are exactly as predicted. Subsiding of the antecedent is triggered by the occurrence of the anaphor 'herself' (ei hun) within the antecedent. The first DP encountered in the top-down derivation and which provides the structural configuration required to satisfy condition A is 'Mary'. Once the 
trigger for subsiding is satisfied, it stops. At the end of the derivation, the object position of 'hear' (clywed) is reached. The resumptive clitic eu is then inserted in the relativization site to check the thematic role of the verb. This analysis accounts for the fact that Nadia cannot be the antecedent of the anaphor 'herself' (ei hun). That is, the only licit antecedent for the anaphor is the first DP encountered in a top-down derivation. Notice that a bottom-up derivation cannot capture this restriction, as the most local antecedent for the anaphor would be Nadia. Welsh resumption data clearly argue in favour of a top-down analysis for reconstruction.

\subsection{Last resort subsiding and appositive relatives in Italian}

Our approach makes another prediction about the last resort property of subsiding. Subsiding should not be triggered if the structural configuration to bind the variable has already been met in the top-down derivation.

This prediction corresponds exactly to unexpected data about appositive relatives in Italian discussed in (Bianchi, 1995). As an illustration, consider the following contrast:

(40) ? Questi aspetti ${ }_{j}$ della propriai personalità, che Gianni $i_{i}$ non riesce ad accettare these aspects of-his own personality which Gianni not able to accept sono emersi nel corso dell'analisi. were emerged in-the course of-the analysis

'These aspects of his ${ }_{i}$ own personality, which Gianni $i_{i}$ was unable to accept, emerged during the psychoanalysis.' 


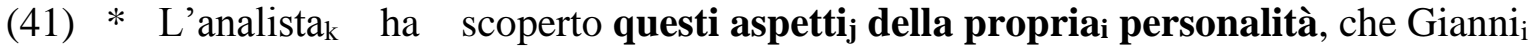
the psychoanalyst has discovered these aspects of-his own personality which Gianni non riesce ancora ad accettare _ $\mathbf{j}$.

not able still to accept

*`The psychoanalyst $\mathrm{k}_{\mathrm{k}}$ discovered these aspects of his $\mathrm{s}_{\mathrm{i}}$ own personality, which

Gianni is still unable to accept.'

(40) is grammatical under the reading where the anaphor is bound by the subject of the appositive relative Gianni. No such reading is available in (41).

This unexpected contrast follows from our top-down approach to reconstruction, and in particular from the fact that subsiding will be triggered only as a last resort operation to bind a pronoun or an anaphor.

The grammaticality of (40) is easily accounted for. The derivation is sketched in (42):

(42)

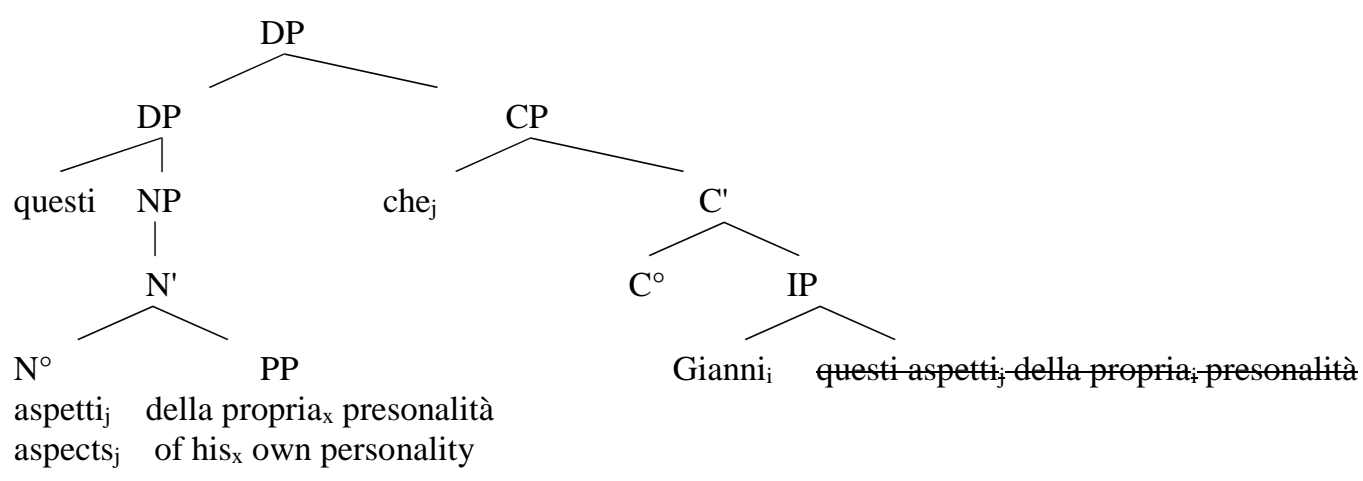

Subsiding is triggered to bind the anaphor propria $_{x}$ embedded within the antecedent of the relative clause. Once Gianni $i_{i}$ is inserted in the derivation, subsiding stops as the anaphor propria can be assigned semantic value (the index $i$ ). The derivation proceeds until the object position of 'accept' (accetare) is met. In this position, $\theta$-motion creates a copy of the operator che (corresponding to which in English). The analysis thus correctly predicts possible coindexing between Gianni and the anaphor. 
Why is this interpretation not available in (41)? The answer is obvious: the required configuration for binding of the anaphor will already be satisfied by another potential antecedent, l'analista $a_{k}$. Consider the derivation of (41):

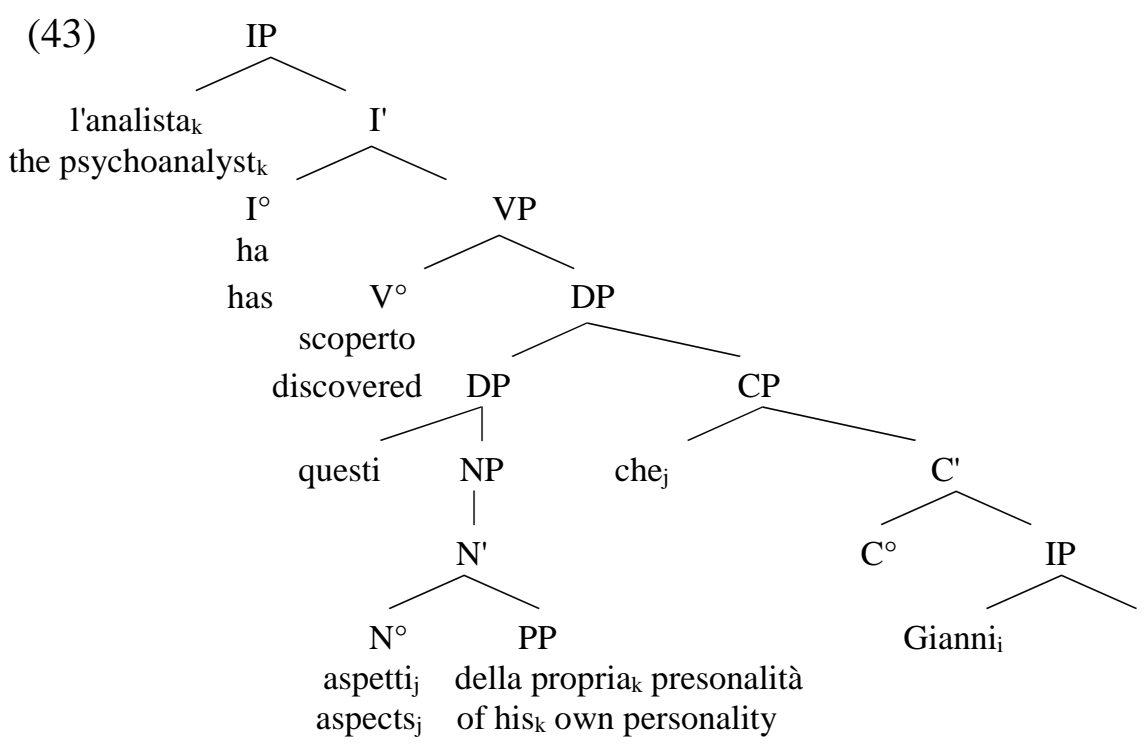

In (41), the head of the appositive relative contains an anaphor. However, the anaphor propria cannot be bound by Gianni within the relative. The ungrammaticality of (41) follows from our analysis. As the derivation proceeds top-down, when the long-distance anaphor propria is merged in the structure, an appropriate antecedent is already provided, namely the DP analista $\mathrm{j}_{\mathrm{j}}$ which can A-bind the anaphor. Since the anaphor can be assigned a semantic value via binding by the DP analista $_{\mathrm{j}}$, there is no trigger for subsiding. The derivation carries on and a copy of the relative operator che is created in the relativization site.

The claim that subsiding is only triggered as a last resort operation correctly predicts that the anaphor cannot be bound by Gianni in (41), but can in (40). 


\section{Conclusion}

This paper provides a novel approach to reconstruction facts which accounts for a very wide range of puzzling data involving the interaction of reconstruction with resumption, appositive relatives and cyclicity. The analysis relies crucially on the fact the semantic derivation proceeds in parallel with the syntactic derivation unfolding in a top-down fashion. Under this view, the semantic calculus, that is the assignment procedure, can itself feed syntactic operations.

\section{References:}

Aoun, J., Choueiri, L. \& Hornstein, N., 2001. Resumption, movement, and derivational economy. Linguistic Inquiry 32, 371-403.

Bergeton, U., forthcoming. The Independence of Binding and Intensification. PhD Thesis, USC, available at http://www-scf.usc.edu/ bergeton/.

Bianchi, V., 1995. Consequences of Antisymmetry for the Syntax of headed Relative Clauses. Doctoral thesis, Scuola Normale Superiore, Pisa.

Büring, D., forthcoming. The Syntax and Semantics of Binding Theory, Cambridge University Press.

Chomsky, N., 1982. Some Concepts and Consequences of the theory of Government and Binding. MIT Press, Cambridge, MA.

Chomsky, N. 1995. The Minimalist Program. MIT Press, Cambridge, MA.

Demirdache, H., 1991. Resumptive Chains in Restrictive Relatives, Appositives and Dislocation Structures. MIT Press, Cambridge, MA.

Fox, D., 2000. Economy and the Semantic Interpretation. MIT Press, Cambridge, MA. 
Grodzinsky, Y. \& Reinhart, T., 1993. The innateness of binding and coreference. Linguistic Inquiry 24, 69-101.

Guilliot, N., 2002. Les trois R en Breton: Relatives, Résomptivité et Reconstruction. Mémoire of DEA, University of Nantes.

Heim, I., 1993. Anaphora and semantic interpretation: a reinterpretation of Reinhart's approach. SFS-Report-07-03, Universität Tübingen.

Heycock, C., 1995. Asymmetries in reconstruction. Linguistic Inquiry 26, 547-570

Jouitteau, M., forthcoming. La Syntaxe Comparée du Breton. Doctoral thesis, University of Nantes.

Kayne, R., 1994. The Antisymmetry of Syntax. MIT Press, Cambridge, MA.

Lebeaux, D., 1990. Relative clauses, licensing, and the nature of the derivation. Proceedings of NELS 20, 318-332, University of MA, Amherst.

Mc Closkey, J., 2002. Resumption, successive cyclicity, and the locality of operations. In: Epstein \& Seely (eds), Derivation and explanation in the minimalist program. Blackwell publishing, pp.184-226.

Nunes, J. \& Uriagereka, J., 2000. Cyclicity and extraction domains. Syntax 3.1, 20-43.

Phillips, C., 1996. Order and Structure. Doctoral thesis, MIT Press, MA.

Pollard, C. \& Sag, I., 1992. Anaphors in English and the scope of Binding Theory. Linguistic Inquiry 23, 261-303.

Reinhart, T., 1995. Interface Strategies. OTS, Universiteit Utrecht.

Reinhart, T., 1997. Strategies of anaphora resolution. OTS working papers.

Reinhart, T. \& Reuland E., 1993. Reflexivity. Linguistic Inquiry 24, 657-720.

Richards, N., 1999. Dependency formation and directionality of tree construction. MITWPL 34: Papers on Morphology and Syntax, Cambridge, MA.

Rouveret, A., 1994. Syntaxe du Gallois. CNRS ed., Paris. 
Rouveret, A., 2002. How are resumptive pronouns linked to the periphery ?. Unpublished ms., University of Paris VII.

Sauerland, U., 1998. The meaning of Chains. Doctoral thesis, MIT Press, Cambridge, MA.

Schachter, P., 1973. Focus and relativization. Language 49, 19-46.

Schlenker, P. 2003. Semantic reinterpretation of binding theory. Proceedings of the Amsterdam Colloquium.

Shlonsky, U. 1992. Resumptive pronouns as a last resort. Linguistic Inquiry 23, 443-468.

Vergnaud, J.-R., 1974. French Relative Clauses. Doctoral thesis, MIT Press, Cambridge, MA.

Willis, D. 2000. On the distribution of resumptive pronouns and wh-trace in Welsh. Journal of Linguistics 36, 531-573. 


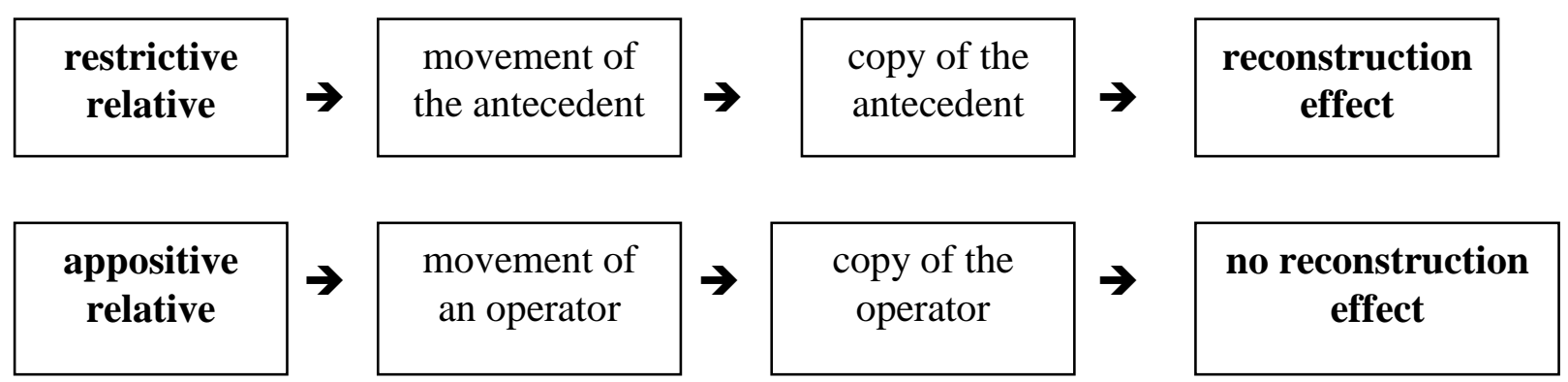

Figure 1:

The asymmetry between restrictive and appositive relatives

for reconstruction facts 


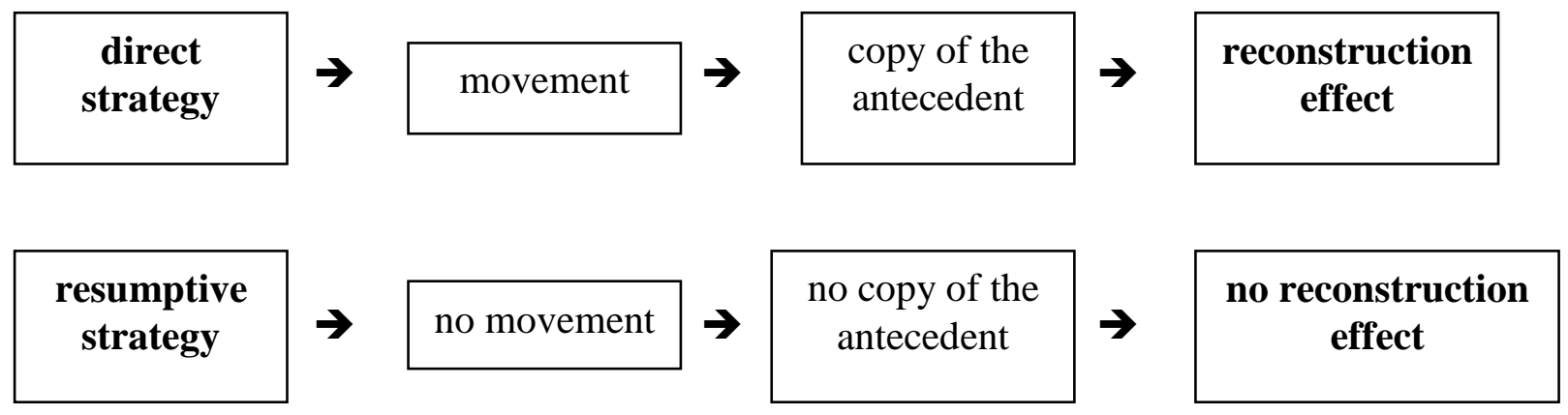

Figure 2:

The asymmetry between direct strategy and resumption

for reconstruction facts 


\begin{tabular}{|c|c|c|}
\hline & $\theta$-motion & Subsiding \\
\hline \multirow{4}{*}{ Properties } & is a top-down mechanism & is a top-down mechanism \\
\hline & is obligatory (feature-checking) & is a last resort device (to bind a variable) \\
\hline & does not have to be cyclic & is cyclic by definition \\
\hline & is subject to locality constraints & is subject to the strong island constraint ${ }^{35}$ \\
\hline Predictions & $\begin{array}{l}\text { reconstruction effect in the } \theta \text {-position } \\
\text { only, with respect to any binding } \\
\text { condition }\end{array}$ & $\begin{array}{l}\text { reconstruction effect in intermediate } \\
\text { sites with respect to Variable Binding } \\
\text { and Condition A }\end{array}$ \\
\hline
\end{tabular}

Table 1:

Properties of $\theta$-motion and Subsiding

$\&$ Predictions 
${ }^{1}$ I am indebted to Mélanie Jouitteau for providing and discussing the data in Breton, and to Hamida Demirdache. I thank David Adger, Joseph Aoun, Danny Fox, Valérie Gautier, Jairo Nunes, Gillian Ramchand and Alain Rouveret for all their comments.

${ }^{2}$ A-Binding: $\alpha$ A-binds $\beta$ iff $\alpha$ c-commands $\beta, \alpha$ and $\beta$ are coindexed, and $\alpha$ occupies an argumental position.

${ }^{3}$ In (Reinhart, 1997), all R-expressions can undergo QR . Moreover, Reinhart distinguishes two readings for a pronoun: a bound variable reading and a covaluation reading, as (i) shows. In this view, condition A is a subset of Variable Binding, as both require Abinding, the only difference lying on the locality property of condition A:

(i) Noa thinks he loves Minia

-Noa $\lambda x$ [x thinks x loves Minia] $\rightarrow$ Bound variable reading

- Noa $\lambda x[\mathrm{x}$ thinks he loves Minia $] \rightarrow$ Covalutation $h e=N o a$.

${ }^{4}$ Both asymmetries are illustrated with relative structures in Breton. However, the second asymmetry between movement and resumption could have been tested with whmovement as well. The prediction is that relativization and wh-movement should exhibit the same patterns.

${ }^{5}$ The head-raising analysis is independently motivated. For arguments, see (Vergnaud, 1974) and (Kayne, 1994).

${ }^{6}$ This particle in Breton ( $a$ or $e$ most of the time) is called `rannig'. It occurs in subordinate and matrix clauses, and is traditionally analyzed as a complementizer. But see (Jouitteau, forthcoming) for an alternative analysis.

${ }^{7}$ We do not provide any grammaticality judgements for the English transcriptions given throughout the paper, as the status of the data in the literature (in particular as regards to weak cross over effects or reconstruction effects in restrictive relatives such as in 
(3)) is at times controversial (see (Schachter, 1973) and (Sauerland, 1998) for conflicting judgements).

${ }^{8}$ The claim that resumption is derived without movement is the default assumption in view of both the absence of island effects and weak crossover effects in Breton. But resumption does not necessarily entail the absence of movement. For example, Rouveret (1994) argues for a derivation of resumption via movement on the basis of island effects in Welsh (at least, strong islands).

${ }^{9}$ Notice that another interpretation of that sentence, which is grammatical, is available in

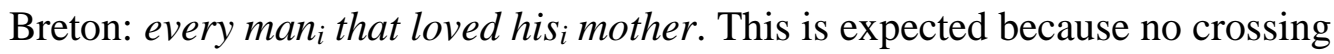
appears in that case (extraction of the subject).

${ }^{10}$ This view of resumption as a last resort strategy is not exactly the same as in (Shlonsky, 1992).

${ }^{11}$ The use of resumption for the extraction of embedded subjects, or within DPs (genitive) or PPs is less surprising as DPs and PPs correspond to sites that are not easily accessible for movement.

${ }^{12}$ Obviously, some other languages such as Irish do not exhibit the same complementary distribution between movement and resumption (see McCloskey, 2002). Irish facts dealing with cyclicity are discussed in footnote 20 .

${ }^{13}$ The anaphor diouti hec'h-unan ('herself') requires at least c-command by its antecedent. Constraints on the locality of this anaphor will be the subject for future research. Owing to space considerations, we do not discuss the logophoric uses of anaphors in this paper. Several authors (Pollard \& Sag, 1992; Reinhart \& Reuland 1993; Bergeton, forthcoming) suggest that anaphors embedded inside DPs are not true anaphors, but rather exempt anaphors or intensifiers. 
${ }^{14}$ On the basis of this puzzling fact, Aoun, Choueiri and Hornstein (2001) propose an analysis based on the existence of two kinds of resumption: apparent resumption derived via movement, and true resumption derived without movement and restricted to cases where islands appear in the derivation. However, this analysis cannot be maintained if you consider reconstruction facts with condition $\mathrm{C}$ (see (12)), i.e. the fact that resumption rescues a condition $\mathrm{C}$ violation.

${ }^{15}$ Another argument (independent of reconstruction facts) has been given in favour of cyclic movement: the distribution of complementizers in Irish (see McCloskey, 2002). However, an interesting alternative is worked out in (Rouveret, 2002), where the morphological shape of the complementizer $(\mathrm{aL})$ is not the consequence of cyclic movement, but rather the trigger for it.

16. $*$ ' indicates a potential reconstruction site, which leads to ungrammaticality (condition C violation).

${ }^{17}$ Technically, in (Fox, 2000), the contrast between (19)a and b follows from what he calls scope reconstruction, which itself follows from the copy theory of movement and deletion of the head of the chain. Fox further argues that these intricate patterns of condition $\mathrm{C}$ effects can be handled only under a syntactic view of reconstruction, where scope reconstruction is determined by the syntax.

${ }^{18}$ In some sense, Both Reinhart (1995) and Fox (2000) appeal to the semantic interpretation of the sentence to legitimate a syntactic movement at LF. Our proposal is different in that it does not compare derivations.

${ }^{19}$ In her approach, only pronouns, anaphors and traces carry indices. QPs and R-expressions don't actually bear indexes. The index is borne by the lambda operator, as (iii) shows: (iii) every boy $\lambda_{\mathrm{i}}\left[\mathrm{t}_{\mathrm{i}}\right.$ called his $\mathrm{s}_{\mathrm{i}}$ mother $]$ 
${ }^{20}$ In this system, only pronouns and anaphors with an index are seen as variables in the sense of Heim (1993). In her approach, deictic pronouns (non-variable uses) are not variables and don't bear any index. In this case, only rules governing coreference (similar to those proposed in (Grodzinsky \& Reinhart, 1993)) drive the reference assignment. See (Heim, 1993: section 1) for further comments.

${ }^{21}$ This section on formal semantics and the semantic calculus is highly simplified. More precisely, the semantic derivation depends on an assignment function $g$ relating integers to individuals (see Büring, forthcoming). R-expressions feed this assignment function as the derivation unfolds top-down. The implementation of the semantic derivation will be further discussed in future work.

${ }^{22}$ To prevent sentences like $*_{w h o}$ did you see John, there should be a constraint that forces any DP (in this case, who) to be thematically related (either by movement in a thematic position or by resumption).

${ }^{23}$ For a discussion on this, see section 1.2.2. Notice, however, that a few authors also proposed locality constraints on resumption, such as the Disjointness Requirement suggested in (Willis, 2000). Nothing from the data in Breton prevents us from having both kinds of locality constraints at work (in movement and in resumption).

${ }^{24} \mathrm{We}$ assume then that the copy of the constituent is deleted since the semantic calculus proceeds throughout the syntactic derivation. Notice that the copy would only be required within a model where the semantic calculus applies after the syntactic derivation.

${ }^{25}$ The use of resumption as a Last Resort Device for the extraction of embedded objects might be due to the nominal properties of the verb in Breton (see 1.2.2 for discussion on this issue). 
${ }^{26}$ Recall that the insertion of the resumptive pronoun is crucial to account for the lack of condition $\mathrm{C}$ effect as no copy of the antecedent appears in the relativization site. This correctly predicts that the absence of resumption will yield a reconstruction effect:

(iv) *pep [poltred Yanni $]_{j}$ en deus pro $_{\mathbf{i}}$ roet __ da Vari every picture Yann prt-has he given to Mary *'every picture of $\mathrm{Yann}_{\mathrm{i}}$ that he $\mathrm{i}_{\mathrm{i}}$ has given to Mary'

${ }^{27}$ The same pattern holds in dislocation structures of Lebanese Arabic, as Aoun, Choueiri and Hornstein (2001) noticed. See the example in (14).

${ }^{28}$ Notice that 'his' $(e)$ could also get its semantic value from the preceding context (the assignment function). Subsiding would obviously not be triggered in this case.

${ }^{29}$ Several authors suggest that anaphors embedded within DPs are not true anaphors subject to condition A (our trigger for subsiding), but rather intensifiers (see Bergeton, forthcoming) or exempt anaphors (see Reinhart \& Reuland, 1993). However, we argue that subsiding would still be required in order for the exempt anaphor to have a bound variable reading (This account is based on the distinction between bound variable readings and covaluation readings, as suggested in (Reinhart, 1997)).

${ }^{30}$ Recall that the same contrast was first noticed by Bianchi (1995) in appositives in Italian.

${ }^{31}$ In principle, our analysis predicts reconstruction effects with variable binding. Recall, however, that (16) repeated below is ungrammatical for independent reasons:

(v) $*$ Poltred $_{\mathbf{j}}$-mañ $\mathbf{e}_{\mathbf{i}}$ verc'h, a gare pep $\operatorname{tad}_{\mathrm{i}} \ldots \mathbf{j}$, a zo bet drailhet. picture-this his father prt liked every father prt is been torn

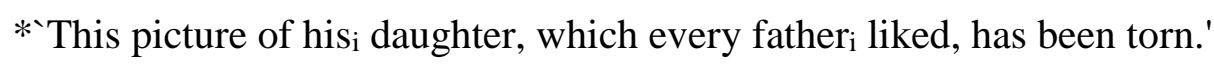

The ungrammaticality of (v) is not due to a lack of reconstruction, but to the semantic incompatibility between variable binding of 'his' which yields a distributed reading of the antecedent and the fact that an appositive relative requires a specific antecedent. In 
other words, subsiding is triggered to bind the pronoun `his' $(e)$, but the derivation crashes because of a mismatch in interpretation (see 2.2 for the argument).

${ }^{32}$ Recall that Fox's analysis is based on the idea of scope reconstruction and is implemented through the copy theory of movement (see 2.3).

${ }^{33}$ The approach advocated here correctly predicts another puzzle studied in (Fox, 2000), the optionality of adjuncts' reconstruction. Compare (vi) and (vii):

(vi) Which claim [ that $\mathrm{John}_{\mathrm{i}}$ made ] was he $\mathrm{i}_{\mathrm{i}}$ willing to discuss ?

(vii) Which of the books [ that he ${ }_{i}$ asked Mrs Brown $n_{j}$ for ] did every student get from her ${ }_{j}$ ? Lebeaux (1990) argues that adjuncts (relative clauses) do not lead to a reconstruction effect (at least with condition C), as (vi) shows. However in (vii), reconstruction of the relative clause is forced. This contrast follows from the approach sketched in this paper, as subsiding of the displaced constituent will only be triggered in (vii) in order to provide a semantic value for the pronoun $h e_{x}$.

${ }^{34}$ My thanks to Alain Rouveret for the data.

${ }^{35}$ Owing to space considerations, we do not justify this property of subsiding, which appears to be confirmed by data in Lebanese Arabic (see Aoun, Choueiri \& Hornstein, 2001). 